\title{
One-year appraisal of a new aortic root conduit with sinuses of Valsalva
}

Ruggero De Paulis, MD

Giovanni Maria De Matteis, MD

Paolo Nardi, MD

Raffaele Scaffa, MD

Dionisio F. Colella, MD

Carlo Bassano, MD

Fabrizio Tomai, MD

Luigi Chiariello, MD

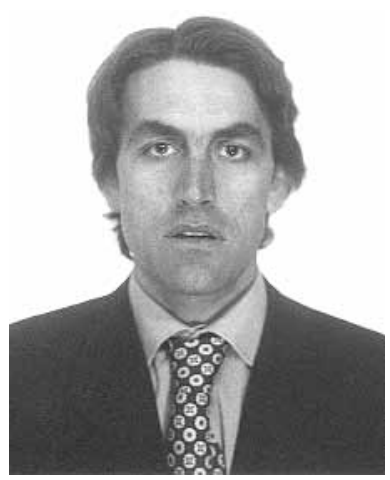

Dr De Paulis
From Cattedra di Cardiochirurgia, Università di Roma Tor Vergata, Rome, Italy.

Received for publication April 4, 2001; revisions requested May 22, 2001; revisions received July 25,2001 ; accepted for publication July 26, 2001

Address for reprints: Ruggero De Paulis, MD, Cattedra di Cardiochirurgia, Università di Roma Tor Vergata, European Hospital, via Portuense 700, 00149 Roma, Italy (E-mail: depauli@tin.it).

J Thorac Cardiovasc Surg 2002;123:33-9

Copyright (C) 2002 by The American Association for Thoracic Surgery

0022-5223/2002 $\$ 35.00+0 \quad \mathbf{1 2 / 1 / 1 1 9 0 6 6}$

doi:10.1067/mtc.2002.119066
Objectives: We evaluate the clinical results 1 year after an anatomic reconstruction of the aortic root in which we used a specifically designed aortic root prosthesis that incorporates the sinuses of Valsalva.

Material and Methods: The new aortic Dacron prosthesis has a proximal portion in the Dacron conduit that expands on implantation, creating pseudosinuses. During a 12-month period, 28 patients (mean age $59 \pm 14$ years) underwent a Bentall operation (12 cases), a remodeling procedure ( 7 cases), and a reimplantation procedure (9 cases) with the use of a new aortic root conduit. All patients had aortic root aneurysm with an anatomically normal (for the valve-sparing procedure) or diseased aortic valve (for the Bentall operation). Five patients had aortic dissection and 5 had Marfan disease. The mean follow-up was $6 \pm 3$ months. All patients underwent postoperative transesophageal and transthoracic echocardiographic studies.

Results: All patients survived and were in good clinical condition at the latest follow-up. Postoperative echocardiography showed a marked reduction in ventricular volumes in all patient groups $(P<.0005)$. In the Bentall group the new prosthesis appeared to reduce the tension on the coronary ostial sutures. In patients undergoing both types of valve-sparing procedures a similar normal anatomy of the aortic root was reconstructed. In the reimplantation group the anulus was smaller than in the remodeling group $(P=.01)$. Patients undergoing the reimplantation procedure had less bleeding and a lower incidence of residual valve insufficiency.

Conclusions: The new aortic root prosthesis allowed the reconstruction of the aortic root anatomy in all types of surgical techniques with low postoperative morbidity.

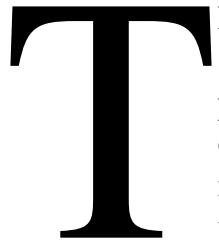

he composite valved graft needed for the Bentall procedure ${ }^{1}$ and the standard Dacron conduit currently used in aortic valve-preserving procedures are not designed to specifically reconstruct the anatomy of the aortic root. The aortic root is a complex region and is of paramount importance in ensuring a normal physiology of the aortic valve motion. The presence of sinuses of Valsalva guarantees a proper opening and a smooth closing of the valve leaflets while greatly reducing their mechanical stress. Therefore, it may be important to maintain this distinct region when replacing the entire ascending aorta. Recently, we have used a new Dacron conduit specifically designed to reconstruct a natural aortic root by incorporating sinuses of Valsalva. We report the clinical results after 1 year of continued use of this prosthesis. 


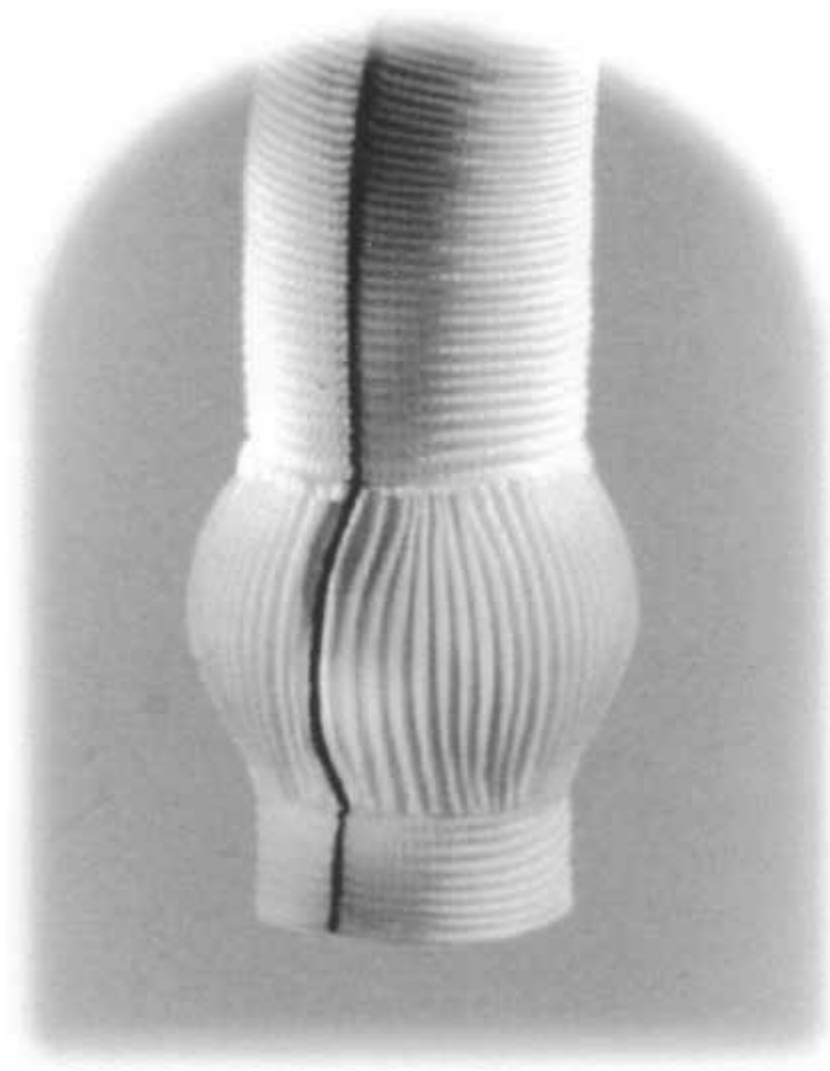

Figure 1. The new aortic Dacron conduit (see text for description).

\section{Methods \\ Dacron Conduit}

The method of manufacturing and the description of this new prosthesis have been reported in detail elsewhere. ${ }^{2}$ In brief, this new prosthesis (Gelweave Valsalva; Sulzer Vascutek, Renfrewshire, Scotland) is a standard Dacron conduit that incorporates a short segment of the same material with corrugations parallel to the conduit long axis. This segment, called a skirt, has a length equal to the graft diameter and is resilient in the horizontal plane so that, on implantation and pressurization, it will generate pseudosinuses of Valsalva. The suture joining these 2 sections of Dacron acts like a new sinotubular junction, and a small collar at the bottom of the skirt completes the design (Figure 1).

By attaching a valve prosthesis to the collar, we obtained a composite valved conduit that was used for the Bentall procedure whenever an aortic root aneurysm was associated with intrinsic disease of the aortic valve leaflets. In all patients with aortic root aneurysm and normal aortic valve leaflets, the new Dacron conduit was used in a remodeling type of valve-sparing procedure ${ }^{3}$ during the first period of our experience, and then it was used in a reimplantation type of valve-sparing procedure. ${ }^{4}$

\section{Surgical Technique}

For all types of operations we followed the surgical steps described by the original authors. ${ }^{1,3,4}$ A few technical details that we think are important to adapt the new prosthesis to the standard procedure are indicated.

Bentall procedure. ${ }^{1}$ After the dilated aortic root and ascending aorta were opened and transected distally, the coronary ostia were isolated on a Carrel patch, the aortic valve was excised, and a series of $U$ stitches of 2-0 braided suture with pledgets were passed below the valve anulus and then, properly spaced, through the valve prosthesis and the collar of the new Dacron conduit. Then, the Dacron conduit and the valve prosthesis were parachuted down to the anulus and the sutures tied. Next, the coronary ostia were reattached to the skirted section of the Dacron graft with a 5-0 polypropylene suture. The prosthesis was then sewn to the distal ascending aorta.

Remodeling procedure. ${ }^{3}$ After the diseased aortic sinuses were excised down to the aortic anulus and the coronary ostia isolated on a Carrel patch, an appropriately sized Dacron conduit was chosen (usually a 28- or 30-mm size graft). After the collar of the new conduit was trimmed, the skirt of the prosthesis was tailored to produce 3 separate tongue-shaped extensions that would fit the 3 sinuses. Care was taken that the 3 extensions would end at the level of the new sinotubular junction. After the top of the 3 commissures were secured to the new sinotubular junction, each extension was sutured to the crescent shape of the aortic valve remnants starting at the nadir of each sinus by means of 3 continuous 4-0 polypropylene sutures. Finally, the coronary ostia were reimplanted into the corresponding sinus with a 5-0 polypropylene suture and the procedure was completed by suturing the conduit to the distal ascending aorta.

Reimplantation procedure. ${ }^{4}$ The aortic sinuses were excised down to the aortic anulus with a few millimeters of aortic wall left above the 3 commissures and the coronary button isolated on a Carrel patch. Multiple horizontal mattress sutures were passed below the aortic valve and outside the aortic wall remnants. A 28or 30-mm Dacron conduit was selected on the basis of the free margin of the leaflet or of the anulus dimension. The collar of the conduit was cut to a minimum. Next, the height of the valve remnants was measured against the length of the skirt of the prosthesis to make sure that once the conduit was sutured to the aortic anulus, the top of the commissures would reach the level of the new sinotubular junction. The sutures were then passed at the appropriate level at the base of the skirt of the conduit and tied down. The graft was cut $2 \mathrm{~cm}$ above the sinotubular junction and the valve remnants were retrieved from inside. The 3 commissures, properly spaced, were stretched and fixed at the new sinotubular junction. Then, the valve remnants were secured to the Dacron wall starting at the nadir of each sinus by means of 3 continuous 4-0 polypropylene sutures. The coronary ostia were reimplanted to the corresponding sinus and the conduit was sutured to the distal ascending aorta. In some cases an extension of the graft was necessary.

\section{Patients and Methods}

Between February 2000 and March 2001 the new aortic root conduit was used in 28 consecutive patients with a diagnosis of aortic root aneurysm and severe valve insufficiency. In 12 patients it was used in a Bentall procedure in association with a mechanical (6 patients) or a biologic valve (6 patients); in 7 patients it was used in the remodeling type of valve-sparing procedure, and in 9 it was 
TABLE 1. Patient characteristics

\begin{tabular}{lcccc}
\hline & Bentall $(\mathbf{n}=\mathbf{1 2})$ & Remodeling $(\mathbf{n}=\mathbf{7})$ & Reimplantation $(\mathbf{n}=\mathbf{9})$ & $P$ value \\
\hline Age $(\mathrm{y})$ & $63.5 \pm 10$ & $58.1 \pm 18.4$ & $55.1 \pm 16.9$ & .4 \\
Sex (M/F) & $10 / 2$ & $5 / 2$ & $8 / 1$ & .6 \\
BSA (m) & $1.89 \pm 0.2$ & $1.98 \pm 0.2$ & $1.88 \pm 0.2$ & .5 \\
EF $(\%)$ & $51 \pm 10$ & $48 \pm 12$ & $59 \pm 9$ & .3 \\
AR $>2$ & $11(91 \%)$ & $6(85 \%)$ & $6(66 \%)$ & .1 \\
NYHA $>2$ & $5(41 \%)$ & $2(28 \%)$ & $2(22 \%)$ & .6 \\
Marfan syndrome & 0 & $2(28 \%)$ & $3(33 \%)$ & .1 \\
Aortic dissection & $3(25 \%)$ & $1(14 \%)$ & $1(11 \%)$ & .3 \\
\hline
\end{tabular}

$B S A$, Body surface area; $E F$, ejection fraction; $A R$, aortic regurgitation; NYHA, New York Heart Association.

TABLE 2. Mean duration of cardiopulmonary bypass (CPB) and crossclamp time

\begin{tabular}{lcccc}
\hline & Bentall & Remodeling & Reimplantation & \multicolumn{1}{c}{} \\
\hline CPB time $(\min )$ & $118.5 \pm 23.1$ & $127 \pm 22$ & $137.8 \pm 23.9^{*}$ & .12 \\
Crossclamp time $(\min )$ & $89.7 \pm 19.1$ & $101 \pm 16$ & $113.4 \pm 9.6 \dagger$ & .0034
\end{tabular}

${ }^{*} P=.04$ versus Bentall group.

$\dagger P=.0008$ versus Bentall group.

used in the reimplantation type of valve-sparing procedure. Patient characteristics are shown in Table 1 . The patients who underwent the Bentall operation had a bicuspid diseased valve, elongated and prolapsing valve leaflets, or a tear in 1 leaflet ( 2 patients had previously been operated on for acute dissecting aneurysm). They received a 23- or 25-mm CarboMedics valve prosthesis (Sulzer Carbomedics Inc, Austin, Tex), a 23-mm St Jude Medical valve prosthesis (St Jude Medical, Inc, St Paul, Minn), a 27-mm Toronto SPV valve (St Jude Medical), a 25-mm Hancock II bioprosthesis (Medtronic, Inc, Minneapolis, Minn), or a 25-mm CarpentierEdwards Perimount pericardial valve (Baxter Healthcare, Irvine, Calif). The other 16 patients had an anatomically normal aortic valve and were selected for a valve-sparing procedure. Because of our previous experience with the remodeling type of valve-sparing procedure, ${ }^{5}$ this technique was adopted in the first 7 patients. In the rest of the patients the new prosthesis was tested by means of the reimplantation technique. Patients with Marfan disease underwent only valve-sparing procedures. One patient who had the reimplantation procedure had acute aortic dissection. Two patients in the reimplantation group had bicuspid valves. Three patients ( 1 who underwent a remodeling operation and 2 who had the Bentall procedure) had associated myocardial revascularization. Hypothermic circulatory arrest was also necessary in 1 patient in the Bentall group.

All patients underwent transesophageal echocardiography immediately after the operation. Those patients who underwent a valve-sparing procedure were enrolled in a research protocol and underwent a second transesophageal echocardiogram $4 \pm 1$ months after the operation. Otherwise, all patients were followed up by telephone interview every 3 months and a transthoracic echocardiogram was scheduled every 6 months. The mean followup for all patients was $6 \pm 3$ months (ranging from 1 to 12 months).

Two-dimensional transesophageal echocardiography was used to assess left ventricular diameter and volumes. Next, the newly reconstructed aortic root was measured at the level of the anulus, at the largest diameter of the sinuses, and at the level of the sinotubular junction. The distance between the open leaflet in full systole and the Dacron aortic wall was also measured. In all groups a proper opening and closing of the aortic valve prosthesis or of the spared natural valve was assessed. Using continuous and pulsedwave Doppler signals, we assessed maximum velocity across the valve and the presence of residual aortic valve regurgitation. The presence of residual aortic valve regurgitation was graded from I to IV on the basis of the ratio of jet height/left ventricular outflow tract height. ${ }^{6}$ Four days after the operation, most of the patients also underwent subtraction digital angiography to visualize the correct dimension and proportion of the aortic root.

The intraoperative and postoperative protocol was approved by the institutional review board, and informed consent was obtained from all participants.

\section{Statistical Analysis}

Analysis of variance was used to compare continuous data among the 3 groups. Nonparametric data were compared by means of the $\chi^{2}$ test. A multiple-way analysis of variance for repeated measures was used to compare preoperative and postoperative ventricular diameter and volumes. Post hoc comparisons were made with the Scheffè $F$ test. Data are indicated as mean \pm 1 SD. All statistical analysis was performed with StatView (version 5.0) for Windows 8.0 software (SAS Institute, Inc, Cary, NC).

\section{Results}

All patients survived and were discharged from the hospital in good clinical condition. The mean cardiopulmonary bypass time and the mean crossclamping time were slightly shorter for the Bentall group than for the remodeling group, and these times were slightly shorter for the remodeling 


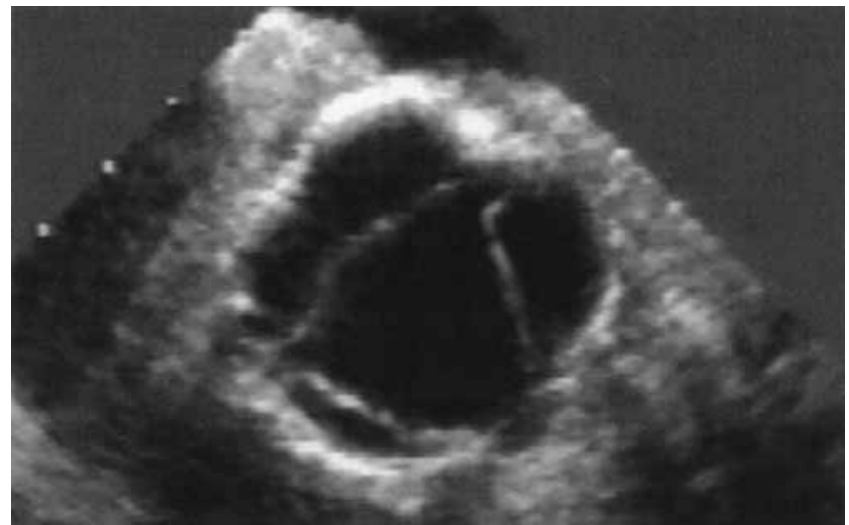

Figure 2. Transesophageal echocardiographic short-axis view of a patient after a remodeling type of valve-sparing procedure with the new conduit.

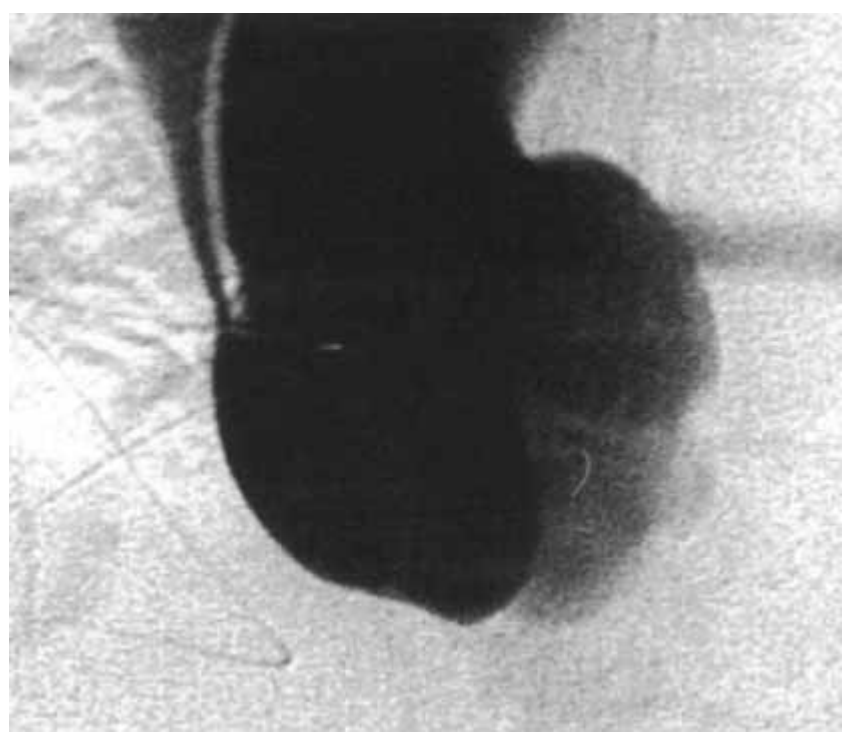

Figure 3. Angiographic view of a patient after a reimplantation type of valve-sparing procedure with the new conduit.

than for the reimplantation group (Table 2). Six patients required a surgical revision for bleeding. There were 4 such cases $(4 / 12 ; 30 \%)$ after a Bentall procedure; in 2 cases a surgical source of bleeding was found at the distal aortic anastomosis and in 2 cases no surgical sources were found. Similarly, after the remodeling procedure 1 patient had active bleeding at the proximal anastomosis and the other patient did not. None of the patients in the reimplantation group required reexploration. One patient in the reimplantation group required sternal rewiring 10 days after hospital discharge. Nine patients (32\%) (3 in each group) had a single episode of atrial fibrillation successfully treated by intravenous amiodarone. The mean postoperative length of
TABLE 3. Echocardiographic parameters preoperatively and at the latest ( \pm 2 months) postoperative echocardiographic follow-up

\begin{tabular}{ccclc}
\hline & Bentall & Remodeling & Reimplantation & Pvalue \\
\hline EDV (mL) & & & & .12 \\
$\quad$ Preop & $268 \pm 75.8$ & $234.4 \pm 55.5$ & $193.3 \pm 86.8$ & \\
Postop & $168.4 \pm 87.2^{*}$ & $157.4 \pm 41.4^{*}$ & $147.4 \pm 35.6^{*}$ & \\
ESV (mL) & & & & .24 \\
$\quad$ Preop & $122 \pm 53.5$ & $118.2 \pm 36.6$ & $78.7 \pm 48.3$ & \\
Postop & $95.4 \pm 62.1^{*}$ & $76.5 \pm 31.9^{*}$ & $67.2 \pm 24.2^{*}$ & \\
EDD (mm) & & & & .12 \\
$\quad$ Preop & $69 \pm 10.2$ & $66.9 \pm 7.2$ & $60.6 \pm 10.8$ & \\
Postop & $56.5 \pm 12.2^{*}$ & $56.3 \pm 6.5^{*}$ & $54.9 \pm 6^{*}$ & \\
ESD (mm) & & & & .14 \\
Preop & $49.3 \pm 9.1$ & $49.3 \pm 6.6$ & $40.7 \pm 10.4$ & \\
Postop & $43.6 \pm 11.6^{*}$ & $40.4 \pm 6^{*}$ & $38.8 \pm 6.5^{*}$ & \\
EF (\%) & & & & .34 \\
Preop & $51 \pm 10$ & $48 \pm 12$ & $59 \pm 9$ & \\
Postop & $46 \pm 10$ & $49 \pm 11$ & $54 \pm 12$ & \\
\hline
\end{tabular}

$E D V$, End-diastolic volume; $E S V$, end-systolic volume; $E D D$, end-diastolic diameter; $E S D$, end-systolic diameter; $E F$, ejection fraction.

${ }^{*} P<.001$ versus preoperative values. $P$ values refer to the comparison among the three groups (the differences could be due to chance).

TABLE 4. Echocardiographic measurements of the reconstructed aortic root

\begin{tabular}{lccc}
\hline & Remodeling & Reimplantation & P value \\
\hline Anulus (mm) & $22.8 \pm 1.6$ & $20.3 \pm 0.7$ & .001 \\
Sinuses (mm) & $38.6 \pm 2.5$ & $36.3 \pm 3.3$ & .19 \\
ST junction (mm) & $28.6 \pm 1$ & $27.4 \pm 1.9$ & .19 \\
Distance, leaflet to wall (mm) & $15.4 \pm 2.9$ & $17.7 \pm 4.4$ & .28 \\
Mean residual valve & $1.1 \pm 0.7$ & $0.8 \pm 0.6$ & .4 \\
$\quad$ insufficiency (1-4) & & & \\
\hline
\end{tabular}

stay for all patients was $9.7 \pm 5.2$ days without important differences among groups. At the last follow-up, all patients were in New York Heart Association class I or II.

At the latest echocardiographic examination (average of $4 \pm 2$ months), all patients had significant reduction of their left ventricular diameters and volumes (Table 3). Patients who received a Bentall operation had normally functioning prosthetic valves, and echocardiography and angiography demonstrated a spherical aortic root with the takeoff of the 2 coronary arteries. This anatomic appearance confirmed the surgeon's perception that the new conduit could in fact decrease the tension on the coronary ostial anastomoses by filling part of the space previously occupied by the aortic root aneurysm.

Five patients undergoing the remodeling type of valvesparing procedure had no or trivial aortic regurgitation, 


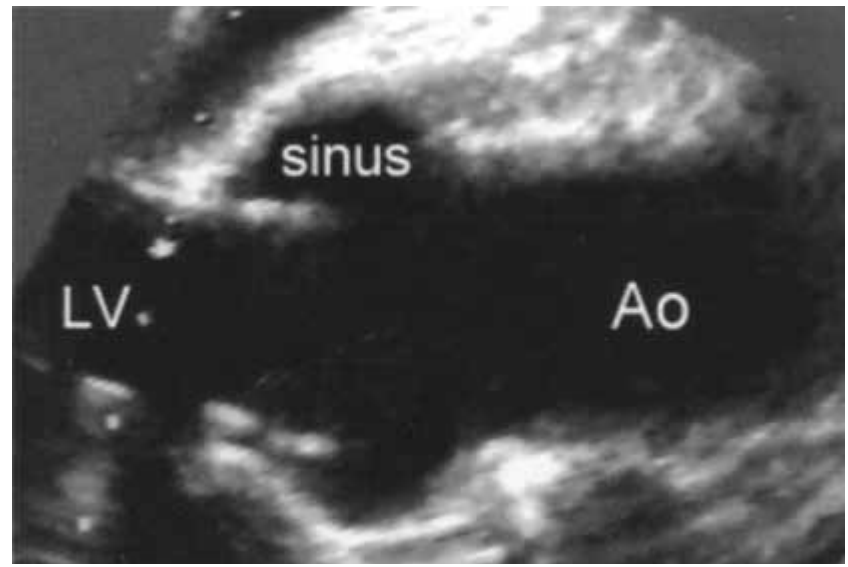

Figure 4. Transesophageal echocardiographic long-axis view of a patient after a reimplantation type of valve-sparing procedure with the new conduit. $L V$, Left ventricle; Ao, aorta.

whereas 2 patients had grade II residual valve insufficiency. The transesophageal echocardiographic long-axis view demonstrated an optimal reconstruction of the natural anatomy of the aortic root with the maintenance of a good proportion between the different diameters of the aortic root. The new sinotubular junction was well defined as a natural narrowing of the ascending aortic diameter. The sinuses were spherical and were deep enough to prevent any systolic contact with the Dacron wall (Figure 2; Table 4).

Eight patients who underwent the reimplantation type of valve-sparing procedure had no or trivial aortic regurgitation, whereas 1 patient with grade II valve insufficiency also had a small prolapse in the noncoronary cusp that was left untreated. The transesophageal echocardiographic longaxis view and the postoperative angiogram showed the reconstruction of a good anatomy of the aortic root identical to that obtained with the remodeling technique; the sinuses were egg-shaped independent pouches and the sinotubular junction was clearly defined (Figures 3 and 4). The short-axis view confirmed the creation of a trifoliate configuration of the root region with 3 separate expansions only at the site of the sinuses, whereas the conduit did not expand at the site of the 3 commissures (Figure 5). The only difference between the 2 techniques was in the diameter of the anulus (Table 4). This was to be expected inasmuch as annular stabilization is a distinct feature of the reimplantation technique. By the use of this new conduit and without major changes in both types of valve-sparing techniques, we observed a similar reconstruction of the aortic root.

\section{Discussion}

Composite valve replacement can be performed with low operative risk and good long-term results. ${ }^{7-9}$ However, a
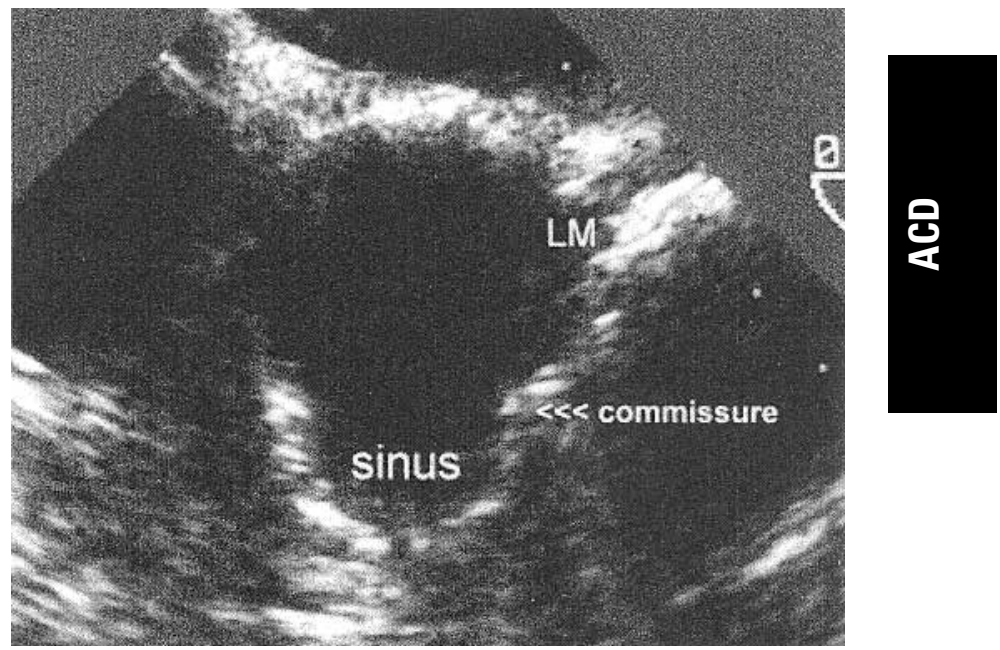

Figure 5. Transesophageal echocardiographic short-axis view of a patient after a reimplantation type of valve-sparing procedure with the new conduit. $L M$, Left main.

surprising number of articles in the literature report technical modifications aimed to prevent bleeding and late pseudoaneurysm by decreasing the tension on the ostial anastomoses. ${ }^{10-16}$ Generally, the open button technique is preferred over the inclusion/wrap technique because it guarantees more tension-free coronary anastomoses. The new conduit used in this study offers the opportunity of obtaining tension-free coronary anastomoses and could be particularly advantageous in those cases in which it can be difficult to detach and mobilize the coronary arteries (ie, calcification, redo operations, fibrosis). In all cases, once the conduit was pressurized with blood, it partially filled the space previously occupied by the aneurysm, thus significantly decreasing the distance between the coronary ostia and the Dacron wall. Problems encountered because of tension at the right coronary anastomosis have recently been reported with the use of standard Dacron conduits. ${ }^{16}$ For its particular geometry the skirt of the new conduit, representing the newly reconstructed aortic root, can only be pulled as a single unit, so that undue tension on the coronary sutures is prevented. The use of this graft with a mechanical valve prosthesis may not offer any flow pattern advantages. However, the presence of vortices into the newly reconstructed aortic root would tend to wash the area of transition between the prosthetic valve and the Dacron conduit, potentially decreasing the incidence of thromboembolism. ${ }^{17}$

Since the innovative techniques of remodeling and reimplantation were introduced into clinical practice, the last decade has witnessed an increasing number of efforts in avoiding the replacement of the aortic valve. The known advantages of avoiding the use of a prosthetic valve and the good results of both types of valve-sparing procedures ${ }^{18-20}$ have widened the surgical indication for this type of proce- 
dures. In the past year, valve-sparing techniques have been successfully used in patients with acute aortic dissection ${ }^{21-23}$ and in patients with bicuspid aortic valves. ${ }^{24}$ Although the remodeling type of valve-sparing procedure with a standard Dacron conduit allows the reproduction of some sort of pseudosinuses, it is virtually impossible to achieve similar results with the technique of reimplantation. ${ }^{25}$ For this reason some modifications to the original reimplantation technique have been devised to avoid any systolic contact between the leaflets and the Dacron wall. ${ }^{26}$ To solve the same problem, we have used a new aortic root prosthesis that allows the reconstruction of egg-shaped sinuses of Valsalva and a well-defined sinotubular junction independently from the surgical technique. In fact, from the postoperative echocardiographic or angiographic images, it is difficult to understand what type of technique has been used. At this point the dilemma whether to choose the remodeling technique rather than the reimplantation technique can no longer be based on the ability of the former technique to obtain a better reproduction of the sinuses of Valsalva. Recently, we compared 2 groups of patients undergoing a remodeling procedure with a standard Dacron conduit and with the new conduit. Using strict transesophageal echocardiographic monodimensional and bidimensional measurements, we demonstrated that the new conduit guarantees a more physiologic valve motion. ${ }^{27}$ As a consequence, by assuring a more physiologic valve motion, the new conduit could improve results even when used in a remodeling type of valve-sparing procedure. Very recently, Zehr and colleagues ${ }^{28}$ used a new conduit with a similar design but custom made to the individual patient's anatomy; they concluded that tear-shaped sinuses might enhance the durability of the valve-sparing operation. Similarly, Grande-Allen and colleagues, ${ }^{29}$ in a finite element study, found that techniques that allow normal sinus space formation result in simulated leaflet stress that is very close to that of normal subjects.

When considering the reimplantation type of valve-sparing procedure, the advantages of the new conduit are more clearly evident. The known advantages of this technique, such as annular stabilization, optimal support of the aortic wall, and decreased chance for bleeding, can now be associated with an optimal reconstruction of the sinuses of Valsalva. On the basis of this preliminary experience, we currently favor the reimplantation technique. First, we noticed that with this type of technique the surgical hemostasis at the end of the procedure was facilitated and the need for surgical revision were minimized. Second, the early follow-up echocardiograms seem to indicate that the reimplantation technique offers more consistent results in terms of residual aortic regurgitation. Finally, it is also possible that the lack of annular stabilization in the remodeling technique could even increase the incidence of valve regurgitation with a longer follow-up period. Indeed, with time the 3 reconstructed sinuses might splay out, with the consequence of recreating a central valve regurgitation. Birks and coworkers, ${ }^{30}$ in their long-term follow-up of the remodeling procedure in a Marfan population, reported that $8.6 \%$ and $23.5 \%$, respectively, of patients with no or mild early postoperative aortic regurgitation underwent reoperation within 5 years. With the new conduit having eliminated the drawback of the lack of sinuses of Valsalva, a long-term follow-up of the reimplantation technique is now warranted to verify whether this procedure can guarantee more stable results.

\section{References}

1. Bentall $\mathrm{HH}$, de Bono A. A technique for complete replacement of the ascending aorta. Thorax. 1968;23:338-9.

2. De Paulis R, De Matteis GM, Nardi P, Scaffa R, Colella D, Chiariello L. A new aortic Dacron conduit for surgical treatment of aortic root pathology. Ital Heart J. 2000;1:457-63.

3. Sarsam MA, Yacoub M. Remodeling of the aortic valve anulus. $J$ Thorac Cardiovasc Surg. 1993;105:435-8.

4. David TE, Feindel M. An aortic valve-sparing operation for patients with aortic incompetence and aneurysm of the ascending aorta. $J$ Thorac Cardiovasc Surg. 1992;103:617-22.

5. Bassano C, De Paulis R, Penta de Peppo A, Tondo A, Fratticci L, De Matteis GM, et al. Residual aortic valve regurgitation after aortic root remodeling without a direct annuloplasty. Ann Thorac Surg. 1998;66: 1269-72.

6. Perry GJ, Helmcke F, Nanda NC, Byard C, Soto BL. Evaluation of aortic insufficiency by Doppler color flow mapping. J Am Coll Cardiol. 1987;94:952-9.

7. Svensonn LG, Crawford ES, Hess KR, Coselli JS, Safi HJ. Composite valve replacement of the proximal aorta: comparison of technique in 348 patients. Ann Thorac Surg. 1992;54:427-39.

8. Gott VL, Gillinov AM, Pyeritz RE, Cameron DE, Reitz BA, Greene PS, et al.Aortic root replacement; risk factor analysis of a seventeenyear experience. J Thorac Cardiovasc Surg. 1995;109:536-45.

9. Dossche KM, Schepens MAAM, Morshuis WJ, de la Rivière AB, Knaepen PJ, Vermeulen FEE. A 23-year experience with composite valve graft replacement of the aortic root. Ann Thorac Surg. 1999; 6:1070-7.

10. Cabrol C, Pavie A, Gandjbakhch I, Villemot JP, Guiraudon G, Laughlin L, et al. Complete replacement of the ascending aorta with reimplantation of the coronary arteries: new surgical approach. $J$ Thorac Cardiovasc Surg. 1981;81:309-15.

11. Kawazoe K, Eishi K, Kawashima Y. New modified Bentall procedure: Carrel patch and inclusion technique. Ann Thorac Surg. 1993;55: 1578-9.

12. Neveux JY, Dervanian P, Folliguet TA, Mace L, Guluta V. Technical modification for anastomosis of low-lying coronary ostia in Bentall procedure. Ann Thorac Surg. 1993;56:383-4.

13. Sarsam MA. A technique for coronary artery reimplantation in composite aortic root replacement. J Card Surg. 1994;9:120-2.

14. Park SB, Maher TD. Modification of the aortic composite graft using the button-in technique. Ann Thorac Surg. 1994;57:1035-6.

15. Petsikas DJ, Ropchan GV. Modified Bentall technique for aortic root replacement: a simplified approach to the short left coronary artery. Can J Surg. 1998;41:463-5.

16. Westaby S, Katsumata T, Vaccari G. Coronary reimplantation in aortic root replacement: a method to avoid tension. Ann Thorac Surg. 1999;67:1176-7.

17. Sauter JA, Campbell LA. Combined prosthetic aortic heart valve and vascular graft. US Patent No. 5,123,919;1992:4.

18. Yacoub MH, Gehle P, Chandrasekaran V, Birks EJ, Child A, Radley- 
Smith R. Late results of a valve-preserving operation in patients with aneurysms of the ascending aorta and root. J Thorac Cardiovasc Surg. 1998; 115:1080-90.

19. Tambeur L, David TE, Unger M, Armstrong S, Ivanov J, Webb G. Results of surgery for aortic root aneurysm in patients with the Marfan syndrome. Eur J Cardiothorac Surg. 2000;17:415-9.

20. Harringer W, Pethig K, Hagl C, Meyer GP, Haverich A. Ascending aortic replacement with aortic valve reimplantation. Circulation. 1999;100(Suppl):II24-8.

21. El Khoury GA, Underwood MJ, Glineur D, Derouck D, Dion RA. Reconstruction of the ascending aorta and aortic root: experience in 45 consecutive patients. Ann Thorac Surg. 2000;70:1246-50.

22. Graeter TP, Langer F, Nikoloudakis N, Aicher D, Schäfers HJ. Valvepreserving operation in acute aortic dissection type A. Ann Thorac Surg. 2000;70:1460-5.

23. Leyh RG, Schmidtke C, Bartels C, Sievers HH. Valve-sparing aortic root replacement (remodeling/reimplantation) in acute type A dissection. Ann Thorac Surg. 2000;70:21-4.

24. Schäfers HJ, Langer F, Aicher D, Graeter TP, Wendler O. Remodeling of the aortic root and reconstruction of the bicuspid aortic valve. Ann Thorac Surg. 2000;70:542-6.
25. Kunzelman KS, Grande KJ, David TE, Cochran RP, Verrier ED. Aortic root and valve relationships: impact on surgical repair. $J$ Thorac Cardiovasc Surg. 1994;107:162-70.

26. Cochran RP, Kunzelman KS, Eddy AC, Hofer BO, Verrier ED. Modified conduit preparation creates a pseudosinus in an aortic valvesparing procedure for aneurysm of the descending aorta. $J$ Thorac Cardiovasc Surg. 1995;109:1049-58.

27. De Paulis R, De Matteis GM, Nardi P, Scaffa R, Buratta M, Chiariello L. Opening and closing characteristics of the aortic valve after valve sparing procedures using a new aortic root conduit. Ann Thorac Surg. 2001;72:487-94.

28. Zehr KJ, Thubrikar MJ, Gong GG, Headrick JR, Robicsek F. Clinical introduction of a novel prosthesis for valve-preserving aortic root reconstruction for annuloaortic ectasia. J Thorac Cardiovasc Surg. 2000;120:692-8

29. Grande-Allen KJ, Cochran RP, Reinhall PG, Kunzelmann KS. Re-creation of sinuses is important for sparing the aortic valve: a finite element study. J Thorac Cardiovasc Surg. 2000;119:753-63.

30. Birks EJ, Webb C, Child A, Radley-Smith R, Yacoub MH. Early and long-term results of a valve sparing operation for Marfan syndrome. Circulation. 1999;100(Suppl):II29-35.

\section{Online-www.aats.org}

Now you can get The Journal of Thoracic and Cardiovascular Surgery online. The Journal online brings you faster delivery time, easy searching of current and back issues, links to PubMed, AATS, WTSA, and other important sites, and more. Visit the Journal online today.

\section{Receive tables of contents by e-mail}

To receive the tables of contents by e-mail, sign up through our Web site at http://www.mosby.com/jtcvs

Choose E-mail Notification

Simply type your e-mail address in the box and click the Subscribe button. Alternatively, you may send an e-mail message to majordomo@mosby.com. Leave the subject line blank and type the following as the body of your message: subscribe jtcvs_toc You will receive an e-mail to confirm that you have been added to the mailing list. Note that TOC e-mails will be sent out when a new issue is posted to the Web site. 